\title{
Determining the Relationship Between Salicylic Acid Levels and Systemic Acquired Resistance Induction in Tobacco
}

\author{
Michael G. Willits and John A. Ryals \\ Novartis Crop Protection, Inc., P.O. Box 12257, 3054 Cornwallis Road, Research Triangle Park, North \\ Carolina 27709-2257, U.S.A. \\ Accepted 5 May 1998.
}

Salicylic acid (SA) has been proposed as the systemic signal for the induction of systemic acquired resistance (SAR). It has been suggested that $\mathrm{SA}$ is synthesized at the site of pathogen-induced necrosis and is translocated to induce SAR in uninfected leaves. Grafting studies between wild-type tobacco plants and plants that are unable to accumulate significant amounts of SA have shown that the large increase in SA accumulation seen in inoculated leaves is not necessary for SAR induction, suggesting that $\mathrm{SA}$ is not the primary systemic signal. However, these studies have not addressed whether decreased levels of SA accumulation in inoculated leaves are sufficient to fully induce SAR. In this study, we have determined the relationship between free SA levels in the inoculated leaf and SAR induction in tobacco. These results support our previous conclusion that $\mathrm{SA}$ is not likely to be the systemic signal.

Additional keywords: tobacco mosaic virus.

Systemic acquired resistance (SAR) is a broad-spectrum resistance that is induced in response to infection by necrotizing pathogens (Hunt and Ryals 1996; Neuenschwander et al. 1996; Ryals et al. 1996). SAR has been studied extensively in tobacco, cucumber, and Arabidopsis thaliana, in which inoculation with necrotizing pathogens leads to both local and systemic increases in salicylic acid (SA) levels, SAR gene expression, and SAR induction (Malamy et al. 1990; Rasmussen et al. 1991; Ward et al. 1991; Uknes et al. 1992, 1993). Many recent studies concerning SAR have investigated the involvement of SA in both local and systemic signaling leading to the induction of resistance.

The application of exogenous SA was shown to mimic certain aspects of a pathogen infection, resulting in both SAR gene expression and SAR induction (White 1979; Ward et al. 1991; Uknes et al. 1992; Vernooij et al. 1995). The physiological relevance of this phenomenon was supported by studies that measured significant increases in endogenous SA levels in both tobacco and cucumber following pathogen

Corresponding author: John A. Ryals, Paradigm Genetics, Inc., P.O. Box 14528, Research Triangle Park, North Carolina 27709-4528;

Telephone: 1-919-544-5578; Fax: 1-919-544-8094

E-mail: Ryals@paradigmgenetics.com infection and prior to SAR induction (Malamy et al. 1990; Métraux et al. 1990). Subsequent studies have established a strong correlation between SA accumulation and SAR induction in tobacco, cucumber, and A. thaliana (Rasmussen et al. 1991; Uknes et al. 1993; Yalpani et al. 1993).

Additional evidence for the involvement of SA in SAR signaling comes from studies that take advantage of techniques that interfere with biosynthetic or degradative pathways for SA, leading to plants with decreased endogenous SA levels. Treatment of $A$. thaliana ecotype Col-0 with 2-aminoindan-2phosphonic acid (AIP), an inhibitor of the enzyme phenylalanine ammonia-lyase (PAL) that carries out the initial step in SA biosynthesis, converted the interaction with Peronospora parasitica isolate EMWA from incompatible to compatible (Mauch-Mani and Slusarenko 1996). Interestingly, this effect was completely reversed by the application of exogenous SA. In tobacco plants epigenetically suppressed in the expression of PAL, reduced SA levels correlated with an inability to activate SAR (Pallas et al. 1996). In tobacco and A. thaliana, expression of a bacterial gene (nahG) encoding salicylate hydroxylase, which converts SA to catechol, resulted in plants that were unable either to accumulate $\mathrm{SA}$ in response to pathogen infection or to mount an induced resistance response (Gaffney et al. 1993; Bi et al. 1995; Friedrich et al. 1995; Lawton et al. 1995).

Although all of these experiments provide strong evidence that SA is required for SAR signaling, they do not address whether SA is the systemic signal responsible for activation of SAR in uninfected tissues. SA has been proposed as this systemic signal because SA levels in the phloem increase significantly following pathogen infection (Métraux et al. 1990; Rasmussen et al. 1991; Yalpani et al. 1991). In support of this idea, in vivo SA-labeling studies have shown that phloem transport of SA produced in infected leaves of tobacco and cucumber accounts for as much as 70 and $14 \%$, respectively, of the SA found in uninfected leaves (Shulaev et al. 1995; Mölders et al. 1996). However, other studies suggest that SA is not the systemic signal. In cucumber, Rasmussen et al. (1991) have shown that an infected leaf can be removed $6 \mathrm{~h}$ after inoculation, which is before SA is detected in the phloem, without affecting systemic increases in SA levels or pathogenesis-related (PR) protein accumulation. In grafting studies between PAL-suppressed tobacco rootstocks and wildtype scions, the reduced SA levels of the rootstocks did not 
affect induction of SAR in the scions (Pallas et al. 1996). Similarly, in grafting studies between nahG-expressing (NahG) tobacco rootstocks and wild-type scions, the dramatic reduction in SA levels seen in NahG plants did not affect the induction of SAR in the scions (Vernooij et al. 1994). These grafting studies demonstrate that reduction of SA levels, resulting either from blocking synthesis or increasing degradation, does not affect transport of the systemic signal, suggesting that SA is not likely to be that signal; however, the involvement of SA in systemic signaling is presently unresolved.

If SA is the systemic signal, then the NahG grafting results would indicate that the production of very low concentrations of SA in the inoculated leaves should completely activate SAR. To test this hypothesis, we have measured the relationship between SA levels and SAR induction as a function of increasing tobacco mosaic virus (TMV) infection. We have found that SAR increases proportionally to the concentration of SA in an inoculated leaf. Based on this relationship, SA concentrations found in TMV-infected NahG rootstocks should not induce SAR in grafted wild-type scions, which is in contrast to the data presented in the NahG grafting study. Therefore, taken together with the NahG grafting results, this study provides strong evidence supporting the conclusion that $\mathrm{SA}$ is not a likely candidate for the systemic signal.

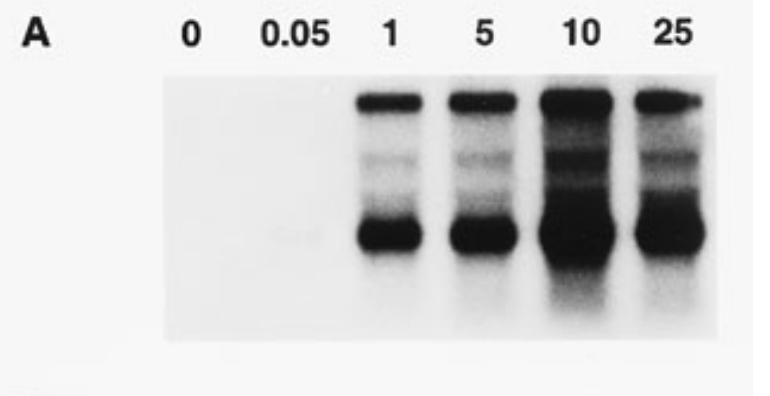

B

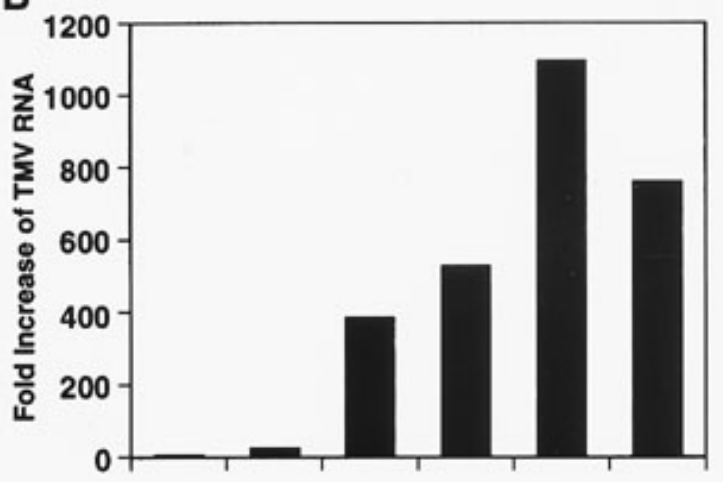

Fig. 1. Analysis of tobacco mosaic virus (TMV) RNA levels. A, Northern (RNA) blot analysis of RNA isolated from inoculated leaves of tobacco plants treated with increasing TMV doses. Number above each lane represents the TMV dose in units of $\mu \mathrm{l}$ of TMV stock per ml of buffer (0.01 M sodium phosphate, $\mathrm{pH}$ 7.0). Filter was hybridized with a TMV coat protein gene probe. B, PhosphorImager analysis of the Northern blot in A. TMV RNA levels were normalized to $\beta$-tubulin message levels and are presented as a fold induction with respect to the buffertreated controls.

\section{RESULTS}

It has been demonstrated previously that the concentration of SA is proportional to the number of lesions in a TMVinoculated leaf (Yalpani et al. 1991). To determine the relationship between SA levels in inoculated leaves and SAR induction, we inoculated lower leaves of tobacco plants with increasing concentrations of TMV and then measured SA and SAR. The range of doses was chosen based on the number of hypersensitive response (HR) lesions that appeared on the inoculated leaves, with the lowest dose leading to approximately 10 to 20 lesions per leaf and the highest leading to nearly confluent necrosis (data not shown).

Actual TMV RNA in the inoculated leaves was measured by Northern (RNA) blot analysis with a TMV coat protein gene probe. This analysis provided a more accurate measurement of the actual TMV dose than obtained by visual inspection of HR necrosis on inoculated leaves. Figure 1A demonstrates the increase in TMV RNA levels in inoculated leaves observed as the TMV dose increased. TMV RNA levels on this Northern blot were quantified by PhosphorImager analysis and normalized to $\beta$-tubulin message levels (Fig. 1B). The reason for the decrease in TMV RNA levels seen with the highest TMV dose is unclear, but this decrease was not reproducible in similar experiments. Free SA was isolated from inoculated leaves of the mock- or TMV-inoculated plants and quantified by high-performance liquid chromatography (HPLC) analysis. These results show that the relationship between TMV RNA levels and SA concentration is nearly linear (Fig. 2).

The results of the previous experiment confirmed that we were able to obtain a series of plants exhibiting increasing concentrations of pathogen-induced SA levels. We measured SAR induction in this series of plants as the percent decrease in HR lesion diameter on uninoculated leaves challenged with TMV. We found that the relationship between free SA levels in inoculated leaves and the percent reduction in lesion diameter in uninoculated leaves was nearly linear (Fig. 3). Furthermore, this relationship was very reproducible, as we obtained similar results in four separate experiments.

\section{DISCUSSION}

SA has been proposed as the systemic signal in SAR because increased SA levels are detected in the phloem following a pathogen infection in cucumber and tobacco (Métraux et al. 1990; Rasmussen et al. 1991; Yalpani et al. 1991). Additionally, in vivo labeling studies have shown that SA produced in inoculated leaves is transported to uninfected tissues (Shulaev et al. 1995; Mölders et al. 1996). If $\mathrm{SA}$ is indeed the systemic signal, then the level of SAR induction should be proportional to the amount of SA produced in the inoculated leaf. However, recent studies have shown that when the accumulation of SA is reduced, there is no effect on the production and transport of the systemic signal. Specifically, we carried out grafting studies between NahG tobacco rootstocks, which are unable to accumulate substantial SA levels, and Xanthi wild-type scions (Vernooij et al. 1994). We found that NahG rootstocks accumulated only $53 \mathrm{ng}$ of SA per $\mathrm{g}$ of tissue following TMV infection, which is 48-fold lower than in wild-type rootstocks; how- 
ever, SAR was fully established in the wild-type scions of the grafted plants.

The NahG grafting study suggests that the concentration of SA in the inoculated leaf is not causally related to the level of SAR induction. However, the possibility exists that very low concentrations of SA in the inoculated leaf could lead to full SAR induction, which would explain why the drastic reduction of SA levels seen in TMV-infected leaves of NahG rootstocks had no effect on the SAR induction in the leaves of grafted Xanthi scions. In essence, SA would saturate the response at a concentration of $53 \mathrm{ng}$ per $\mathrm{g}$ of tissue. Figure 4A presents a relationship that describes this hypothesis and represents the relationship between SA concentration and SAR induction that would be expected in wild-type plants in order for both the proposal of SA as the systemic signal and the NahG grafting results to be correct. Data points 1 and 2 represent actual measurements of SA levels and lesion diameters in mock-inoculated (point 1) or TMV-inoculated (point 2) leaves from grafted plants containing NahG rootstocks and Xanthi scions (Vernooij et al. 1994). Data point 3 represents the same measurements from TMV-inoculated leaves of a Xanthi/Xanthi grafted control plant (Vernooij et al. 1994). In this relationship, the level of SAR induction would be proportional to the SA concentration in the inoculated leaf, but would be saturated at very low SA levels. Increases in SA concentration above this threshold level would not affect SAR. In order to account for possible experimental error in the NahG grafting study, we will assume that the measured SA concentration in

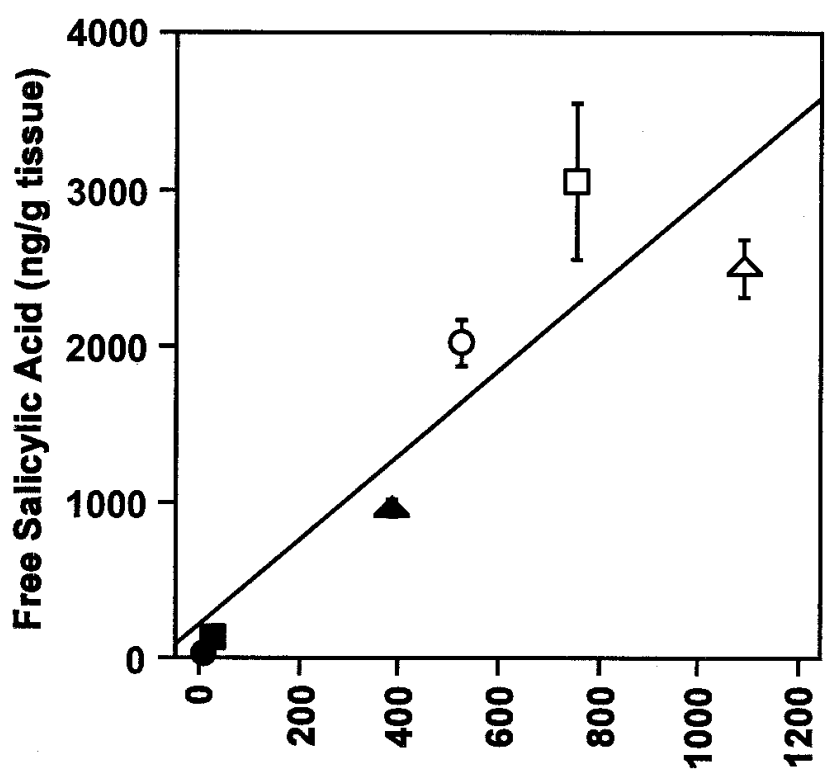

Fig. 2. Free salicylic acid (SA) levels in the inoculated leaf in response to increasing tobacco mosaic virus (TMV) RNA. TMV RNA levels were determined as described in Figure 1B. SA levels were measured from frozen tissue by high-performance liquid chromatography (HPLC) analysis and are reported as the mean of triplicate samples in units of ng of SA per $\mathrm{g}$ of tissue. Symbols are as follows: closed circle, buffer treated; closed square, $0.05 \mu \mathrm{l}$ of TMV per ml of buffer; closed triangle, $1 \mu \mathrm{l}$ of TMV per ml of buffer; open circle, $5 \mu \mathrm{l}$ of TMV per $\mathrm{ml}$ of buffer; open triangle, $10 \mu \mathrm{l}$ of TMV per $\mathrm{ml}$ of buffer; open square, $25 \mu \mathrm{l}$ of TMV per ml of buffer.
TMV-infected leaves of NahG rootstocks is actually 10 -fold higher, a concentration of $530 \mathrm{ng}$ per $\mathrm{g}$ of tissue (Fig. 4B, point $2^{\prime}$ ). In this scenario, the SA/SAR relationship would look like the curve in Figure 4B. Therefore, for the proposal of SA as the systemic signal to be consistent with the NahG grafting results, the SA/SAR relationship in wild-type tobacco should fall between the curves in Figure 4A and B.

An alternative model is that SA is not the translocated signal but is somehow involved in signal transduction. In this model, the relationship between the SA concentration in the infected leaves and the level of SAR induction is not causal and is therefore not bound by the results found in the NahG grafting study. In this scenario, the relationship between SA and SAR in wild-type plants could fall within a range bordered by the curve in Figure $4 \mathrm{~B}$ and a completely linear relationship (Fig. 4C). An SA/SAR relationship falling within the shaded region would indicate that SA is not the systemic signal. When the measured data are compared with the models, it is clear that the data fall within the shaded region in Figure 4C (Fig. 4D). This result indicates that the SA/SAR relationship in tobacco is not consistent with SA being the systemic signal. Furthermore, based on the measured relationship between SA and SAR (Fig. 3), at levels of SA detected in NahG rootstocks, $53 \mathrm{ng}$ per $\mathrm{g}$ of tissue, there should be very little induction of SAR in grafted wild-type scions. Thus, the results of these experiments, taken together with the NahG grafting data, argue that SA is unlikely to be the systemic signal and that the synthesis and release of the systemic signal are not linked to the accumulation of SA.

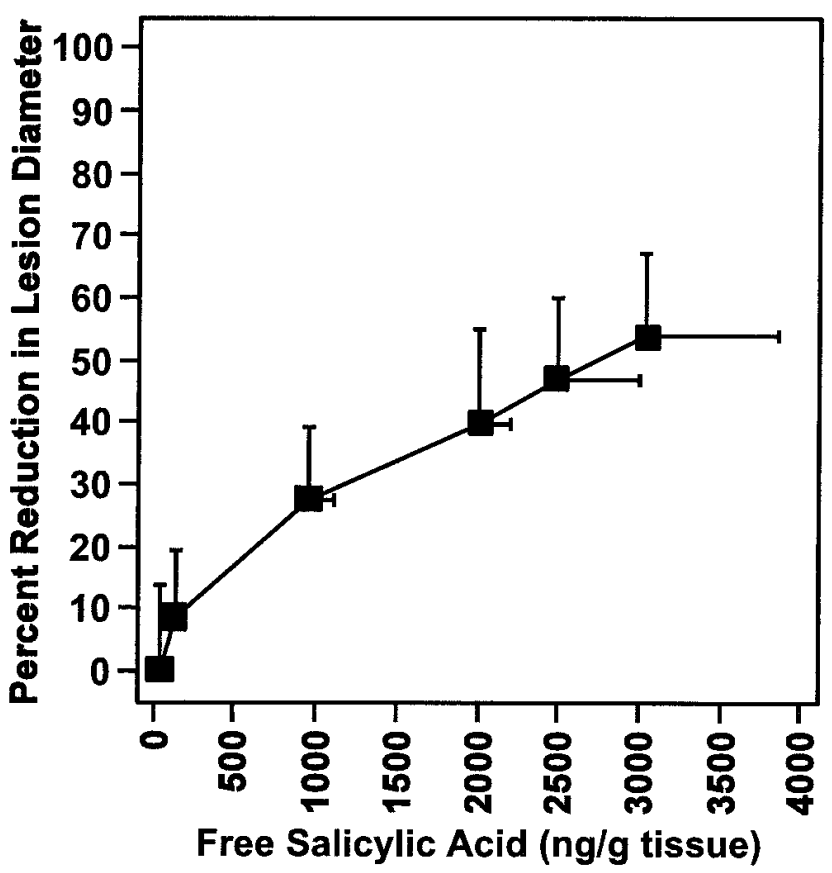

Fig. 3. Relationship between free salicylic acid (SA) levels in the inoculated leaf and systemic acquired resistance (SAR) induction. SA levels are described in Figure 2. SAR was measured as the percent decrease in lesion diameter on uninoculated leaves challenged with tobacco mosaic virus (TMV) 7 days after the primary inoculation. Each data point represents the mean of 90 lesion diameters. 
The importance of SA in the induction of disease resistance is well established. Following pathogen attack, SA accumulates inside the cell and is likely an intermediate signal between pathogen perception and gene induction. The fact that SA produced in infected leaves can be transported to uninfected tissue is also well documented; however, this transport is apparently not essential for the full induction of $\mathrm{SAR}$ in tobacco. Further investigations examining the spe-
A

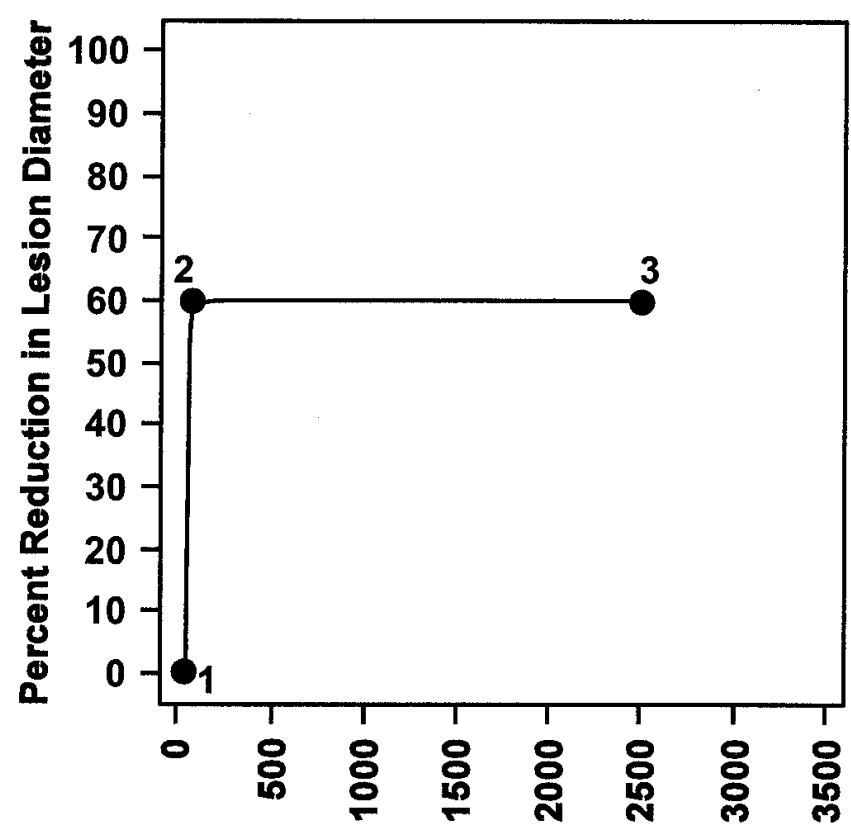

C

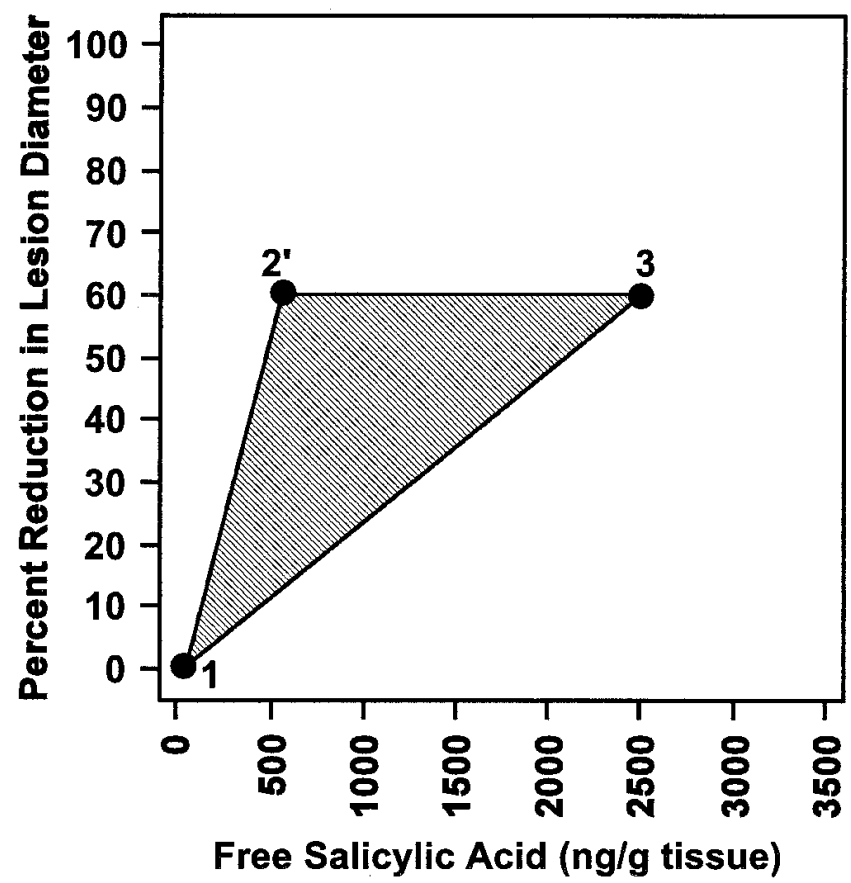

B

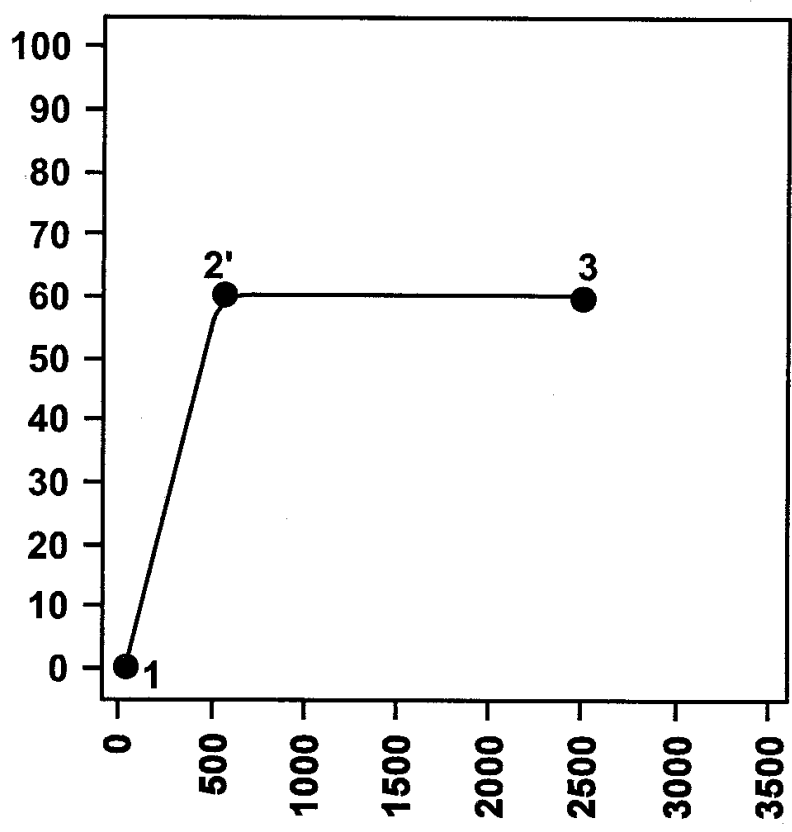

D

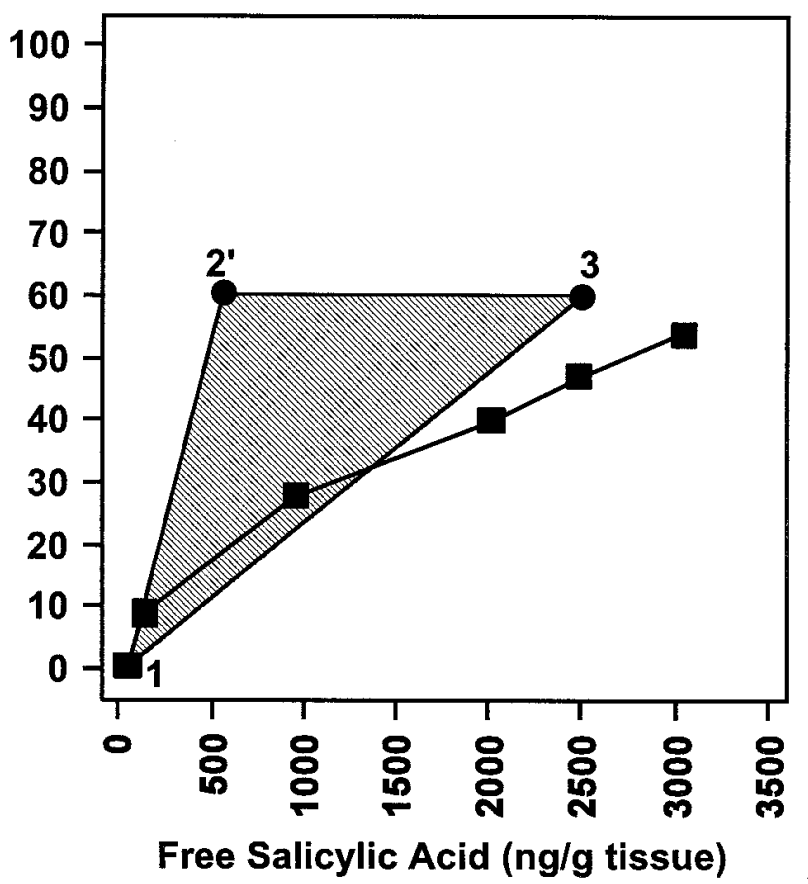

Fig. 4. Hypothetical relationships between salicylic acid (SA) levels and systemic acquired resistance (SAR) induction. A, Graph represents data measured in the Vernooij et al. (1994) NahG grafting study. Data points represent the free SA level and percent reduction in lesion diameter from mockinoculated (point 1) or tobacco mosaic virus (TMV)-inoculated (point 2) leaves of NahG rootstock/Xanthi scion grafted plants, or TMV-inoculated leaves from a Xanthi/Xanthi grafted plant (point 3). B, Point 2' assumes that the SA measurement used in point 2 (53 ng per g of tissue) is actually 10fold higher (530 ng per g of tissue). C, Graph diagrams an alternate hypothesis in which SA is not the systemic signal. Shaded area represents a continuum of SA/SAR relationships that would be inconsistent with proposals of SA as the systemic signal, based on the NahG grafting data. D, Overlay of Figure 3 and Figure 4C. 
cific role of SA in disease resistance and the identity of the systemic signal should provide a clearer understanding about the signaling mechanisms responsible for the activation of SAR.

\section{MATERIALS AND METHODS}

\section{Plant material and treatment.}

Six- to 8-week-old Xanthi-nc tobacco plants were inoculated with increasing doses of TMV (U1 strain) or buffer as previously described (Gaffney et al. 1993). Three lower leaves were inoculated on each of three plants with $0,0.05$, $1,5,10$, or $25 \mu \mathrm{l}$ of TMV per ml. After 7 days, one inoculated and one uninoculated leaf were removed from each plant for RNA and SA analyses. The three inoculated leaves treated with the same dose of TMV were combined and ground for analysis; uninoculated leaves were combined in the same manner. In order to measure SAR induction, three uninoculated leaves from each plant were challenged with TMV. After 5 days the diameter of 10 lesions per leaf were measured.

\section{RNA analysis.}

Total RNA was isolated from frozen tissue samples by phenol-chloroform extraction followed by lithium chloride precipitation (Lagrimini et al. 1987). For Northern blot analysis, $10-\mu$ g total RNA samples were electrophoretically separated on formaldehyde-agarose gels and blotted to nylon membranes (GeneScreen Plus, NEN Research Products, Boston) as previously described (Ausubel et al. 1987). Ethidium bromide was included in the sample buffer at 40 $\mu \mathrm{g} / \mathrm{ml}$ to allow photography under UV light before blotting to confirm equal loading of RNA. DNA for the TMV probe was prepared as a reverse transcriptase-polymerase chain reaction product containing the coat protein gene from TMV. ${ }^{32} \mathrm{P}$-labeled probes were prepared from the TMV DNA with the Random Primers DNA Labeling System (Gibco BRL, Rockville, MD), while unincorporated nucleotides were removed with the NucTrap Probe Purification System (Stratagene, La Jolla, CA). Hybridization and washing conditions were carried out as previously described (Church and Gilbert 1984). Northern blots were quantified with a PhosphorImager (Molecular Dynamics, Sunnyvale, CA) and TMV RNA levels were normalized to $\beta$-tubulin message levels.

\section{SA analysis.}

Free SA was isolated and quantified from frozen tissue samples as previously described (Gaffney et al. 1993). Extractions were performed in triplicate and averaged. SA values were corrected for recovery, based on an extraction efficiency of $44 \%$.

\section{ACKNOWLEDGMENTS}

We wish to thank Kay Lawton, Leslie Friedrich, and other members of the Ryals laboratory for technical advice and useful discussions concerning the experiments. Also, we wish to thank Kay Lawton and Michelle Hunt for critically reading the manuscript.

\section{LITERATURE CITED}

Ausubel, F. M., Brent, R., Kingston, R. E., Moore, D. D., Seidman, J. G., Smith, J. A., and Struhl, K. 1987. Current Protocols in Molecular Biology. Vol. 1. John Wiley and Sons, New York.

Bi, Y.-M., Kenton, P., Mur, L., Darby, R., and Draper, J. 1995. Hydrogen peroxide does not function downstream of salicylic acid in the induction of PR protein expression. Plant J. 8:235-245.

Church, G. M., and Gilbert, W. 1984. Genomic sequencing. Proc. Natl. Acad. Sci. USA 81:1991-1995.

Friedrich, L., Vernooij, B., Gaffney, T., Morse, A., and Ryals, J. 1995. Characterization of tobacco plants expressing a bacterial salicylate hydroxylase gene. Plant Mol. Biol. 29:959-968.

Gaffney, T., Friedrich, L., Vernooij, B., Negrotto, D., Nye, G., Uknes, S., Ward, E., Kessmann, H., and Ryals, J. 1993. Requirement of salicylic acid for the induction of systemic acquired resistance. Science 261:754-756.

Hunt, M., and Ryals, J. 1996. Systemic acquired resistance signal transduction. Crit. Rev. Plant Sci. 15:583-606.

Lagrimini, L. M., Burkhart, W., Moyer, M., and Rothstein, S. 1987. Molecular cloning of complementary DNA encoding the ligninforming peroxidase from tobacco: Molecular analysis and tissuespecific expression. Proc. Natl. Acad. Sci. USA 84:7542-7546.

Lawton, K., Weymann, K., Friedrich, L., Vernooij, B., Uknes, S., and Ryals, J. 1995. Systemic acquired resistance in Arabidopsis requires salicylic acid but not ethylene. Mol. Plant-Microbe Interact. 8:863-870.

Malamy, J., Carr, J. P., Klessig, D. F., and Raskin, I. 1990. Salicylic acid: A likely endogenous signal in the resistance response of tobacco to viral infection. Science 250:1002-1004.

Mauch-Mani, B., and Slusarenko, A. 1996. Production of salicylic acid precursors is a major function of phenylalanine ammonia-lyase in the resistance of Arabidopsis to Peronospora parasitica. Plant Cell 8: 203-212.

Métraux, J.-P., Signer, H., Ryals, J., Ward, E., Wyss-Benz, M., Gaudin, J., Raschdorf, K., Schmid, E., Blum, W., and Inverardi, B. 1990. Increase in salicylic acid at the onset of systemic acquired resistance in cucumber. Science 250:1004-1006.

Mölders, W., Buchala, A., and Métraux, J.-P. 1996. Transport of salicylic acid in tobacco necrosis virus-infected cucumber plants. Plant Physiol. 112:787-792.

Neuenschwander, U., Lawton, K., and Ryals, J. 1996. Systemic acquired resistance. Pages 81-106 in: Plant-Microbe Interactions. Vol. 1. G. Stacey and N. T. Keen, eds. Chapman and Hall, New York.

Pallas, J. A., Paiva, N. L., Lamb, C., and Dixon, R. A. 1996. Tobacco plants epigenetically suppressed in phenylalanine ammonia-lyase expression do not develop systemic acquired resistance in response to infection by tobacco mosaic virus. Plant J. 10:281-293.

Rasmussen, J. B., Hammerschmidt, R., and Zook, M. N. 1991. Systemic induction of salicylic acid accumulation in cucumber after inoculation with Pseudomonas syringae pv. syringae. Plant Physiol. 97:1342-1347.

Ryals, J. A., Neuenschwander, U. H., Willits, M. G., Molina, A., Steiner, H.-Y., and Hunt, M. D. 1996. Systemic acquired resistance. Plant Cell 8:1809-1819.

Shulaev, V., León, J., and Raskin, I. 1995. Is salicylic acid a translocated signal of systemic acquired resistance in tobacco? Plant Cell 7: 1691-1701.

Uknes, S., Mauch-Mani, B., Moyer, M., Potter, S., Williams, S., Dincher, S., Chandler, D., Slusarenko, A., Ward, E., and Ryals, J. 1992. Acquired resistance in Arabidopsis. Plant Cell 4:645-656.

Uknes, S., Winter, A., Delaney, T., Vernooij, B., Morse, A., Friedrich, L., Nye, G., Potter, S., Ward, E., and Ryals, J. 1993. Biological induction of systemic acquired resistance in Arabidopsis. Mol. PlantMicrobe Interact. 6:692-698.

Vernooij, B., Friedrich, L., Ahl Goy, P., Staub, T., Kessmann, H., and Ryals, J. 1995. 2,6-Dichloroisonicotinic acid-induced resistance to pathogens without the accumulation of salicylic acid. Mol. PlantMicrobe Interact. 8:228-234.

Vernooij, B., Friedrich, L., Morse, A., Reist, R., Kolditz-Jawhar, R., Ward, E., Uknes, S., Kessmann, H., and Ryals, J. 1994. Salicylic acid is not the translocated signal responsible for inducing systemic acquired resistance but is required in signal transduction. Plant Cell 6:959-965 
Ward, E. R., Uknes, S. J., Williams, S. C., Dincher, S. S., Wiederhold, D. L., Alexander, D. C., Ahl-Goy, P., Métraux, J.-P., and Ryals, J. 1991. Coordinate gene activity in response to agents that induce systemic acquired resistance. Plant Cell 3:1085-1094.

White, R. F. 1979. Acetylsalicylic acid (aspirin) induces resistance to tobacco mosaic virus in tobacco. Virology 99:410-412.

Yalpani, N., Shulaev, V., and Raskin, I. 1993. Endogenous salicylic acid levels correlate with accumulation of pathogenesis-related proteins and virus resistance in tobacco. Phytopathology 83:702708.

Yalpani, N., Silverman, P., Wilson, T. M. A., Kleier, D. A., and Raskin, I. 1991. Salicylic acid is a systemic signal and an inducer of pathogenesis-related proteins in virus-infected tobacco. Plant Cell 3:809-818. 